\title{
Human Resources Information Systems: Transactional and Strategic Paradigm
}

\author{
Anton Florijan Barišić \\ University VERN, Croatia \\ Mirjana Pejić Bach \\ University of Zagreb, Faculty of Economics and Business \\ Ivan Miloloža \\ University of Osijek, Faculty for Dental Medicine \& Health
}

\section{Abstract}

Human resources information system (HRIS) is an inevitable element of contemporary organisation's setup. The HRIS provides multiple human resources management (HRM) services from operational assistance in collecting, storing and preparing data, executing and controlling processes, reducing HRM labour costs, and providing information to the management enabling them to make quality HR strategic decisions. This paper is aimed in contributing to the better utilization of HRIS usage in organizations, analysing various approaches in terms of purposefulness and validity of implementation of HRIS with the goal to maximize its impact to organizational performance. The goal of the paper is to provide the overview of HRIS transactional and strategic paradigm, and evaluate its impact to organizational performance.

Keywords: management, human resources, human resources information system, outsourcing, organizational performance

JEL classification: M10, O32, O33, L25, M55

\section{Introduction}

Processes of globalisation and increasing competition are continuous and irreversible. Consequently, organisations themselves and their interactions with the business environment are becoming more and more complex (Buller et al., 2012; Beadles et al., 2015). That complexity, reflected in the organisation's setup (architecture and size), changing organisational culture and diverse labour force requires from management to face growing number of challenges in running daily business operations (Shilpa et al., 2011; Buller et al., 2012; Ababneh et al., 2014). Therefore, as various studies proved, the needs and requirements of the different and complex contemporary workforce cannot be satisfied through classical HR management approach (Dhiman, 2015; Ababneh et al., 2014; Bhuiyan et al., 2015).

The implementation of information and communication technologies (ICT) has been recognised as a solution for rapidly growing problem in management of human resources in the organisations. A significant potential of new technologies in satisfying needs of HRM function has enabled the development and implementation of the human resource information systems (HRIS) (Kundu et al., 2012; Dhiman, 2015). Various authors argue that implementation of ICT transforms HRM function into flexible, strategy oriented and cost efficient system enabling organisations to achieve competitive advantage and improving its overall performance (Kundu et al., 2012; Zafar, 2013; Ababneh et al., 2014). The use of ICT in HRM supports and improves decision-making processes, ensures quick response rates in communication with 
different stakeholders within and outside organisation, provides high quality services, and accommodate cultural changes due to diverse workforce and environments in which organisations operate (Ferdous et al., 2015; Kumar et al., 2012).

Diverse surveys associated with HRIS are conceptual and non-empirical studies. Using either a qualitative or quantitative approach, the large range of surveys have explored the situation in the HRIS usage and integrated HR services (Ahmer, 2013; Delmotte et al., 2012; Marler et al., 2013; Bhuiyan et al., 2015). The two extremes in exploring the potential benefits of HRIS are its exclusive use as an administrative tool and its complex strategic use, although their definitive goal is increase of organizational value and efficiency (Shilpa et al., 2011). Taking into account these various approaches, the goal of the paper is to provide the overview of the development of the notion of HRIS from the transactional HRIS to strategic HRIS paradigm.

\section{Transactional HRIS Paradigm}

In the early stages of its development, HR function has been considered as Personnel administration covering activities such as employee enrolment, payroll and benefits administration, hiring, and firing employees (Shilpa et al., 2011; Rao et al., 2012). Human resource management and human capital approaches have emerged in later stage of the development when has been recognised the importance of HR function in accomplishing organisational business strategy (Bhuiyan et al., 2015). In that respect, Personnel administration evolved into HR, which further expanded into two different but interrelated directions known as strategic and transactional HR. Although being two separate constituents, transactional and strategic HR cannot operate separately (Shilpa et al., 2011).

The early studies, starting with 1980s, have explored the stages in the HRIS development and have found that almost about 40 percent organizations do not use HRIS (Sadiq et al., 2013; Beadles et al., 2015). Some other studies have evidenced relatively poor HRIS adoption rate (Rao et al., 2012; Hayek et al., 2013; Ferdous et al., 2015). Studies that are more recent have explored operation and relationships of the HRIS to the management information system (MIS) function (Delmotte et al., 2012; Ahmer, 2013). Sadia et al. (2013), and Beadles et al. (2015), have explored the adoption of HRIS compared to the size of the organisation and have found that small size organizations are more reluctant in implementation of HRIS

A transactional $H R$, in delivering its administrative functions such as payroll and benefit administration, establishing and executing workplace guidelines, and solving workplace problems, is analogous to the personnel administration department (Bhuiyan et al., 2015; Batt et al., 2016). Because the transactional activities are, in general, process oriented affairs; HR professionals conduct and manage these activities through all the phases of an employment relationship from selection, recruitment, and hiring of new employees to termination of work and firing of an existing employee (Zafar, 2013; Findikli et al., 2016).

\section{Strategic HRIS Paradigm}

Strategic HR is considered as proactive approach to the HR, containing progressive concepts and ideas, and thus complementing the organizational business strategy, mission, values and culture by establishing long-term objectives supported by implementing functional HR activities (Ujunju, 2012; Sadiq et al., 2013; Beadles et al., 2015). In that respect, strategic HRM function serves as strategic business partner creating engaged, motivated and committed workforce with superior skills and 
competences capable to contribute to achievement of organisational performance and competitive advantage (Rao et al., 2012; Bhuiyan et al., 2015).

The extensive restructuring of organisations started in late 1990s, was followed by massive outsourcing of transactional HR services such as payroll and benefits administration, employee training and development, hiring and firing of employees, and from other side, the merging these activities into an internal HR information system enabling employees to manage personal HR related activities in form of a "self-service" (Shilpa et al., 2011; Sadiq et al., 2013; Patro, 2016).

Due to the radical changes caused with processes of globalisation and changes in organisational functioning, human resources (HR) function is forced to change and become more strategic using new technologies to provide its services more efficient and effective (Kundu et al., 2012; Bhuiyan et al., 2015). Some authors argue that due to the development and adoption of ICT in HR processes and emerging of new organisational forms, the traditional HR function is disappearing (Ujunju, 2012; Zafar, 2013). Such a development includes shift towards functional HRM design comprising shared services approach, centres of expertise concept containing, according to Ulrich model, a team of HR professionals, and establishment of HR business partners (Kundu et al., 2012; Sotiropoulos, 2014; Bhuiyan et al., 2015). The advantages of that threefold design are reduced transactional costs for shared services routine operations, delivery of effective and high quality HR services, and possibility to concentrate on strategic value added performance enhancing activities (Shilpa et al., 201 1; Alam et al., 2016).

\section{Impact of HRIS to organizational performance}

Several studies estimate that majority of HR departments use their working time approximately on (Ababneh et al., 2014; Pani et al., 2015): (i) transactional activities $65 \%$ to $75 \%$; (ii) traditional activities $15 \%$ to $30 \%$, and (iii) transformational activities $5 \%$ to $15 \%$.

Authors indicate that HRIS provides effective organization track on (Sotiropoulos, 2014; Yakusak, 2015): 'Paid time off (PTO) and attendance, Pay scale history, Positions and pay grades, Overall performance development strategies, Coaching obtained, Disciplinary actions, Personal staff data, Key staff succession plans, Identification of prospective staff, and Applicant administration, including interview process and selection'. These researchers indicate that most of the HRIS functions origins from the transactional perspective.

However, other authors report that HRIS can increase productivity and reduce response times accelerating processing of information, minimizing data inaccuracy, improving the tracing, and monitoring employee activities (Kundu et al., 2012; Shaheen et al., 2014). Some additional benefits of using HRIS and reasons to use HRIS are: (i) improved HR operations and thus enhanced effectiveness, (ii) ability to generate diverse range of HR reports, (iii) transition to strategic HRM instead of transactions processing, and (iv) restructure the entire organisational HR function.

The reward management as a connection between performances and the contents of the employee's compensation package is usually associated with the performance lifecycle (Delmotte et al., 2012; Bhuiyan et al., 2015).

From the strategic perspective, a HRIS may be an instrument used to invoke, monitor and control employee attitudes and behaviours locally (Delmotte et al., 2012) and globally (Al-Dmour et al., 2014; Dhiman, 2015).

The organisational competitive advantage and achievement of strategic goals depend in great measure on human capital and knowledge creation, which gives HRM function strategic importance (Buller et al., 2012; Bhuiyan et al., 2015). Some 
studies argue that the effectiveness and capacity of the HRM system can describe how accumulated individual employee qualities affect organizational effectiveness (Buller et al., 2012; Beadles et al., 2015). In that sense, the principal goal of HR strategy is to establish and effectively manage the process of developing and deploying organizational and human capital to gain and sustain enhanced competitive advantage and organisational performance (Rao et al., 2012; Sotiropoulos, 2014).

The research studies highlight the fact that the HRM function due to its complexity, process intensity and variety of procedures and information is one among last remaining management functions intended for automation and digitalisation which indicates complexity and difficulties in developing one such a comprehensive system in comparison with some other organisational business functions (Obeidat, 2012; Sotiropoulos, 2014; Sareen, 2015). This type of HRIS can be considered as the ideal model because it generates a range of information critical for effective decisions making processes including the organisation's HR services, and consequently it can be considered as a benchmark for adoption and implementation of an HRIS in the organisation (Delmotte et al., 2012; Bhuiyan et al., 2015).

Therefore, the notion of strategic HRIS, takes into account that HRM is an organisational function designed to maximize employee performance in achieving organisational strategic objectives and competitive advantage (Marler et al., 2013; Bhuiyan et al., 2015). HRM is particularly focused on policies and systems aimed at successful and effective management of employees within an organisation, providing a diverse range of activities, such as staffing, employee training, employee performance evaluation, legal \& regulatory HR issues, remuneration and reward packages and industrial relations (Swaroop, 2012; Maier et al., 2013).

Utilisation of an HRIS enables a knowledge creation, workforce administration and professional development and growth (Dhiman, 2015; Findikli et al., 2016). Additionally, to the managers HRIS provides a quicker access to the information required for effective assistance to the labour processes and workforce management (Kumar et al., 2012; Bhuiyan et al., 2015).

Overall, the digitalised and in great measure automated HRM function accelerate the possibility of implementation of effective solutions and identifying strategic goals and business outcomes (Kumar et al., 2012; Sadiq et al., 2013; Sotiropoulos, 2014). From the perspective of the HRM, adoption of ICT influences the entire workforce, generating notable financial yield (Zafar, 2013; Yakusak, 2015).

The literature suggests that there is twofold impact of technology in HRM to be considered; the influence on the HR function itself and an influence on the effectiveness of the HR processes delivery (Delmotte et al., 2012; Johnson et al., 2016). Regarding the effectiveness of HR processes, empirical surveys prove that HRIS implementation reduces costs of process execution (Nivlouei, 2014; Bhuiyan et al., 2015; Findikli et al., 2016).

\section{Conclusion}

The analysis of relevant literature related to transactional and strategic paradigm of HRIS showed that the implementation of HRIS and use of its integrated features could in essence change the way in which organisation's human resources communicate to each other improving the information and expertise flow and thus increasing organizational strategic capabilities. However, this change can only occur if HRIS is implemented and used in organizations taking into account its strategic perspective.

Our review revealed that various researchers argue that HRIS contains an inherent possibility to essentially impact organisation's channels of earning incomes. 
Regarding the benefits derived from utilisation of HRIS features, organisation can enjoy a considerable competitive advantage and organisational performance using improved HR decision-making processes with significant influence on productivity, cost reductions, and product quality etc.

Finally, the results of our reivew on HRIS implementation can be presented in a form of recommendations but also limitations for its adoption:

- The use of HRIS leads to considerable improvement of HR function effectiveness and thus achievement of an organisational competitive advantage,

- The HRIS can contribute to effective employee and organisational performance with regard to volume and diversity of generated HR reports,

- The HRIS can participate in shifting HR practice from transaction processing to strategic HRM implying also needs for new profile of HR staff capable to serve as analyst evaluating HR activities in relation to the organisation's development plan,

- The HRIS enables employees themselves to participate in the HR activities by using HR self-service where they can verify and correct their personal information,

- The HRIS containing integrated applications enables an organisation to radically restructure its entire HR function integrating and automating a diverse range of tasks previously carried out by HR professionals.

\section{References}

1. Ababneh, H. T., Shrafat, F. D. (2014), "Human Capital Information Systems: An Introduction", International Journal of Business and Management, Vol. 9, No. 9, pp. 193-204.

2. Ahmer, Z. (2013), "Adoption of human resource information systems innovation in Pakistani organizations", Journal of Quality and Technology Management, Vol. 9, No. 2, pp. 22-50.

3. Alam, M. G. R., Masum, A. K. M., Beh, L. S., Hong, C. S. (2016), "Critical Factors Influencing Decision to Adopt Human Resource Information System (HRIS) in Hospitals", PloS one, Vol. 11, No. 8, available at:

http://journals.plos.org/plosone/article?id=10.1371/journal.pone.0160366 (5 March 2017)

4. Al-Dmour, R. H., Zu'bi, M. F. (2014), "Factors motivating and inhibiting the practice of HRIS in business organizations: An empirical analysis", International Business Research, Vol. 7, No. 7, pp. 139-155.

5. Beadles, I. I., Aston, N., Lowery, C. M., Johns, K. (2015), "The impact of human resource information systems: an exploratory study in the public sector", Communications of the IIMA, Vol. 5, No. 4, pp. 39-46.

6. Bhuiyan, F., Rahman, M. M., Gani, M. O. (2015), "Impact of Human Resource Information System on Firm Financial Performance", International Journal of Business and Management, Vol. 10, No. 10, pp. 171-185.

7. Buller, P. F., McEvoy, G. M. (2012), "Strategy, human resource management and performance: Sharpening line of sight", Human resource management review, Vol. 2, No. 1, pp. 43-56.

8. Delmotte, J., De Winne, S., Sels, L. (2012), "Toward an assessment of perceived HRM system strength: scale development and validation", The International Journal of Human Resource Management, Vol. 23, No. 7, pp. 1481-1506.

9. Dhiman, M. C. (2015), "An investigation of e-HRM practices in Indian tourism and hospitality industry", in Kumar, S., Dhiman, M. C., Dahiya, A. (eds.), International tourism and hospitality in the digital age, IGI Global, Hershey, pp. 88-102.

10. Ferdous, F., Chowdhury, M. M., Bhuiyan, F. (2015), "Barriers to the implementation of 
human resource information systems", Asian journal of management sciences and education, Vol. 4, No. 1, pp. 33-42.

11. Findikli, M. A., Rofcanin, Y. (2016), "The concept of e-HRM, its evolution and effects on organizational outcomes", in Machado, C., Davim, J. P. (Eds.), Technological challenges and management: matching human and business needs (1st edition), CRC Press, Boca Raton, pp. 35-51.

12. Hayek, M., Hayek, C., Williams Jr, W. A. (2013), "Implication of SOX Compliance for HRM: Enhancing Internal Controls with E-HRM", Journal of Applied Management and Entrepreneurship, Vol. 18, No. 4, pp. 18-37.

13. Johnson, R. D., Lukaszewski, K. M., Stone, D. L. (2016), "The evolution of the field of human resource information systems: Co-evolution of technology and HR processes", Communications of the Association for Information Systems, Vol. 38, No. 28, pp. 533553.

14. Kumar, D. M., Pandya, S. (2012), "Leveraging technology towards HR excellence", Information management and business review, Vol. 4, No. 3, pp. 205-229.

15. Kundu, S. C., Kadian, R. (2012), "Applications of HRIS in Human Resource Management in India: A Study", European Journal of Business and Management, Vol. 4, No. 21, pp. 34-41.

16. Maier, C., Laumer, S., Eckhardt, A., Weitzel, T. (2013), "Analyzing the impact of HRIS implementations on HR personnel's job satisfaction and turnover intention", The Journal of Strategic Information Systems, Vol. 22, No. 3, pp. 193-207.

17. Marler, J. H., Fisher, S. L. (2013), "An evidence-based review of e-HRM and strategic human resource management", Human Resource Management Review, Vol. 23, No. 1, pp. 18-36.

18. Nivlouei, F. B. (2014), "Electronic human resource management system: The main element in capacitating globalization paradigm", International Journal of Business and Social Science, Vol. 5, No. 2, pp. 147-159.

19. Obeidat, B. Y. (2012), "The relationship between human resource information system (HRIS) functions and human resource management (HRM) functionalities", Journal of Management Research, Vol. 4, No. 4, pp. 192-211.

20. Pani, S., Panigrahi, S., Kaur, R., Chitranshi, J. (2015), "Effectiveness of Human Resource Information System on HR Functions of an Organization", Management Dynamics, Vol. 15, No. 2, pp. 112-135.

21. Patro, C. (2016), "Impulsion of information technology on human resource practices", in Ordóñez de Pablos, P. (Ed.), Managerial strategies and solutions for business success in Asia, IGI Global, Hershey, pp. 231-254.

22. Rao, S. L. N., Kollur, A. A. (2012), "Perception of Employees' and Management Towards HRIS Module with Department Levels of Respondents in KPCL Company," International Journal of Organizational Behaviour \& Management Perspectives, Vol. 1, No. 2, pp. 145-149.

23. Sadiq, U., Ahmad Fareed Khan, K. I., Mujtaba, B. G. (2013), "The Impact of Information Systems on the Performance of Human Resources Department", Journal of Business Studies Quarterly 2012, Vol. 3, No. 4, pp. 77-91.

24. Sareen, P. (2015), "Study of employee satisfaction towards e-HRM system", European Journal of Applied Business and Management, Vol. 1, No. 1, pp. 17-33.

25. Shaheen, I., Ghazanfar, F., Hussain, S. (2014), "The role of HRIS in achieving organizational excellence: a multifaceted discussion", International Journal of Physical and Social Sciences, Vol. 4, No. 12, pp. 14-27.

26. Shilpa, V., Gopal, R. (2011), "The implications of implementing electronic-human resource management (e-HRM) systems in companies", Journal of Information Systems and Communication, Vol. 2, No. 1, pp. 10-22.

27. Sotiropoulos, P. (2014), "HRM innovation through technology in Greece: factors influencing the adoption, diffusion and exploitation of e-HRM and social media", Doctoral dissertation, University of Glasgow.

28. Swaroop, K. R. (2012), "E-HRM and how it will reduce cost in the organization", Asia Pacific Journal of Marketing and Management Review, Vol. 1, No. 4, pp. 133-139. 
29. Ujunju, M. O. (2012), "Evaluating the role of information and communication technology (ICT) support towards processes of management in institutions of higher learning", Editorial Preface, Vol. 3, No. 7, pp. 56-67.

30. Yakusak, E. (2015), "Examining the recent technological changes in the aspect of HRM practice: a case study of HR practitioners in Headhunt International", Doctoral dissertation Dublin Business School.

31. Zafar, H. (2013), "Human resource information systems: Information security concerns for organizations", Human Resource Management Review, Vol. 23, No. 1, pp. 105-113.

\section{About the authors}

Dr. sc. Anton Florijan Barisic is senior lecturer at the University for applied sciences VERN, Zagreb. He obtained his PhD degree at Fakulteta za komercialne in poslovne vede, Celje, Slovenia. He studied and perfected his knowledge at universities in Croatia, Italy, Germany and Poland. Within Erasmus + programme he hold lectures at the University Maya, Porto, Portugal, Fakulteta za komercialne in poslovne vede, Celje, Slovenia and Helena Chodkowska University of Management and Law, Warsaw, Poland. As an author or co-author, he wrote about 50 scientific and professional papers, case studies and articles. As a project manager or key expert, he participated in the realization of a series of projects funded by the EU in Croatia and Southeast Europe, in the areas of human resource development, public sector reform, local economic development and entrepreneurship development. He is also working as an expert for international institutions such as EU Commission, EBRD, WB and UNDP. He holds a world certificate for management consultants, (CMC), serves as certified European Excellence Auditor, and is a member of number of international professional bodies and associations. The author can be contacted at afbarisic@chronos.hr.

Mirjana Pejić Bach is a Full Professor at the Department of Informatics at the Faculty of Economics \& Business. She graduated at the Faculty of Economics \& Business Zagreb, where she also received her Ph.D. degree in Business, submitting a thesis on "System Dynamics Applications in Business Modelling" in 2003. She is the recipient of the Emerald Literati Network Awards for Excellence 2013 for the paper Influence of strategic approach to BPM on financial and non-financial performance published in Baltic Journal of Management. Mirjana was also educated at MIT Sloan School of Management in the field of System Dynamics Modelling, and at OliviaGroup in the field of data mining. She participates in number of EU FP7 projects, and is an Expert for Horizon 2020. The author can be contacted at mpejic@efzg.hr.

Asisstant Professor Ivan Miloloža, Ph.D. graduated from the Faculty of Economics and Business in Zagreb and received a Ph.D. at the Faculty of Economics in Osijek in 2015. He lived and worked abroad in the period from 1983 to 1986 (Argentina and the Netherlands). Since 1986, he has been employed by Munja, the only Croatian battery manufacturer, where he has performed virtually all management functions and is currently the CEO of the Board (since 1999). Currently, he is Assistant Professor at the Department of Dental Medicine and Health, Dean for Institutional Cooperation and Development and Chair of the Department of History of Medicine and Social Sciences. In addition, Ivan has performed many social functions in various state bodies, associations and banks, and was a participant and guest lecturer at numerous domestic and foreign faculties and international conferences. The author can be contacted at ivan.miloloza@fdmz.hr. 